\title{
A Case Report of Hemophagocytic Lymphohistiocytosis Secondary to Disseminated Tuberculosis
}

\author{
Shuwen Lin, MD \\ Thomas Jefferson University, shuwen.lin@jefferson.edu \\ Christoher Terry \\ Thomas Jefferson Univeristy, christopher.terry@jefferson.edu
}

Follow this and additional works at: https://jdc.jefferson.edu/tmf

Part of the Internal Medicine Commons

Let us know how access to this document benefits you

\section{Recommended Citation}

Lin, MD, Shuwen and Terry, Christoher (2020) "A Case Report of Hemophagocytic Lymphohistiocytosis Secondary to Disseminated Tuberculosis," The Medicine Forum: Vol. 21 , Article 10.

DOI: https://doi.org/10.29046/TMF.021.1.009

Available at: https://jdc.jefferson.edu/tmf/vol21/iss1/10

This Article is brought to you for free and open access by the Jefferson Digital Commons. The Jefferson Digital Commons is a service of Thomas Jefferson University's Center for Teaching and Learning (CTL). The Commons is a showcase for Jefferson books and journals, peer-reviewed scholarly publications, unique historical collections from the University archives, and teaching tools. The Jefferson Digital Commons allows researchers and interested readers anywhere in the world to learn about and keep up to date with Jefferson scholarship. This article has been accepted for inclusion in The Medicine Forum by an authorized administrator of the Jefferson Digital Commons. For more information, please contact: JeffersonDigitalCommons@jefferson.edu. 


\title{
A Case Report of Hemophagocytic Lymphohistiocytosis Secondary to Disseminated Tuberculosis
}

\author{
Shuwen Lin, MD, Christopher Terry, MD
}

\section{INTRODUCTION}

Hemophagocytic lymphohistiocytosis $(\mathrm{HLH})$ is a life-threatening disorder characterized by excessive activation of the immune system causing tissue damage and organ dysfunction. Secondary HLH is more common in adults and is usually triggered by infection, malignancy, rheumatologic, and immunodeficiency syndromes. We present a case of HLH secondary to disseminated tuberculosis (TB).

\section{CASE PRESENTATION}

A 72-year-old woman with past medical history of hypertension and type 2 diabetes presented to the emergency department for one day history of fevers, poor oral intake, and fatigue. She was febrile to $102.9 \mathrm{~F}$ and noted to have a toxic appearance, but there were no focal abnormalities found on exam. Initial blood work was notable for a mild direct hyperbilirubinemia of $2.5 \mathrm{mg} / \mathrm{dL}$, AST/ALT of 162/112 IU/L and elevated INR of 1.4. Abdominal ultrasound showed gallbladder wall thickening. Due to concerns for ascending cholangitis, ERCP was performed and revealed a normal biliary system. Day 2 of hospitalization revealed new pancytopenia - her white blood cell count was $2.7 \mathrm{~B} / \mathrm{L}$ with $44 \%$ bands, hemoglobin was 10.8 $\mathrm{g} / \mathrm{dL}$, and platelet count was $39 \mathrm{~B} / \mathrm{L}$. She also had rising hepatic function tests. Her ferritin on day 3 was significantly elevated at $4149 \mathrm{IU} / \mathrm{L}$, raising concerns for HLH. On day 4, the patient became increasingly tachypneic and tachycardic with radiographic findings of pulmonary edema despite diuresis, as well as acute kidney injury with decreased urine output. She was intubated for increased work of breathing. Due to a high suspicion of HLH with the probability of HLH greater than $99 \%$ calculated by the HScore, methylprednisolone $120 \mathrm{mg}$ daily in split doses was initiated. Etoposide was not started due to her multiorgan dysfunction. On day 5, her liver and kidney failure worsened, and her ferritin and triglycerides continued to rise. She also developed hypofibrinogenemia concerning for DIC. On day 6, methylprednisolone was changed to dexamethasone 8mg Q6 and anakinra $100 \mathrm{mg}$ Q12 was added, but this was discontinued on day 7 when her liver biopsy showed many caseating and non-caseating granulomas with AFB stain positive for acid-fast bacilli. Sputum AFB stains were also obtained positive for acid fast bacilli. Sputum PCR showed Mycobacterium tuberculosis (TB) leading to the presumptive diagnosis of $\mathrm{HLH}$ secondary to disseminated TB. Due to the patient's acute liver failure, a modified regimen of TB treatment was initiated including rifampin, ethambutol, levofloxacin, and amikacin. Despite TB treatment, immunosuppression for $\mathrm{HLH}$, and supportive measures, the patient continued to deteriorate and expired on day 10 .

\section{DISCUSSION}

Although HLH secondary to TB (TB-HLH) has previously been reported in the medical literature, it remains a rare entity. ${ }^{1}$ Most patients with TB-HLH had short symptom duration and rapid progression leading to multi-organ dysfunction and ultimately, death.

The first HLH treatment protocol was published in 1994 $(\mathrm{HLH}-94)$ and has been widely used in clinical practice. HLH-94 includes an anti-inflammatory agent, dexamethasone, and a pro-apoptotic agent, etoposide. This regimen has been shown to improve survival but was primarily based on data in the pediatric setting, many with primary HLH. ${ }^{2}$ Furthermore, etoposide was not determined to be a safe option due to her multi-organ dysfunction. Instead, anakinra, an IL-1 receptor antagonist was used in combination of dexamethasone. Anakinra as an immunomodulator has also been shown to be effective in the treatment of severe HLH in the critical care setting. ${ }^{3-4}$

Additionally, secondary HLH is often triggered by an acute infection or other condition (eg, rheumatologic condition) and treatment should be to address the underlying cause of immune activation. Although there is no consensus of standard treatment for TB-HLH, a systematic review of the international literature demonstrates that a delay or absence of antitubercular therapy (ATT) were associated with decreased survival. ${ }^{5}$ On the contrary, the combination of antitubercular therapy (ATT) with immunotherapy has been found to significantly reduce mortality. ${ }^{1}$ Our patient was initiated on a modified regimen of ATT as soon as the diagnosis of disseminated TB was made, but she still passed several days later. This case highlights the need for ongoing investigation for early detection and management of secondary HLH in the adult setting. 
The Medicine Forum, Vol. 21 [2020], Art. 10

\section{REFERENCES}

1. Zhang, Y., Liang, G., Qin, H., Li, Y., \& Zeng, X. (2017). Tuberculosis-associated hemophagocytic lymphohistiocytosis with initial presentation of fever of unknown origin in a general hospital. Medicine, 96(16). doi: 10.1097/ md.0000000000006575

2. Henter, J.-I. (2002). Treatment of hemophagocytic lymphohistiocytosis with HLH-94 immunochemotherapy and bone marrow transplantation. Blood, 100(7), 2367-2373. doi: 10.1182/blood-2002-01-0172

3. Rajasekaran, S., Kruse, K., Kovey, K., Davis, A. T., Hassan, N. E., Ndika, A.N., Birmingham, J. (2014). Therapeutic Role of Anakinra, an Interleukin-1 Receptor Antagonist, in the Management of Secondary Hemophagocytic Lymphohistiocytosis/Sepsis/Multiple Organ Dysfunction/Macrophage Activating Syndrome in Critically III Children*. Pediatric Critical Care Medicine, 15(5), 401-408. doi: 10.1097/pcc.0000000000000078

4. Wohlfarth, P., Agis, H., Gualdoni, G. A., Weber, J., Staudinger, T., Schellongowski, P., \& Robak, O. (2017). Interleukin 1 Receptor Antagonist Anakinra, Intravenous Immunoglobulin, and Corticosteroids in the Management of Critically III Adult Patients With Hemophagocytic Lymphohistiocytosis. Journal of Intensive Care Medicine, 34(9), 723-731. doi: $10.1177 / 0885066617711386$

5. Padhi, S., Ravichandran, K., Sahoo, J., Varghese, R., \& Basheer, A. (2015) Hemophagocytic lymphohistiocytosis: An unusual complication in disseminated Mycobacterium tuberculosis. Lung India, 32(6), 593. doi: 10.4103/0970-2113.168100 